\title{
ANNOUNCEMENT
}

\author{
RAMI - 93 \\ Seventh International Congress on Rapid Methods and Automation in Microbiology and \\ Immunology
}

\section{Tomorrow's Techniques}

\section{Imperial College, London 12-15 September 1993}

\section{Scientific programme}

Topics will include:

Point of use diagnostic testing; Arthropod-borne infections; Nucleic acid analysis; Human retrovirus infections; Immunoassays; Chlamydial infections; Bacterial growth monitoring/blood culture; Foodborne pathogens; Environmental agents; Parasitic diseases; Emerging pathogens (+ prions); Mycobacterial infections; Antibiotic resistance; Hepatitis; Biological modifiers; Quality control/assurance/accreditation; Mycoses; Flow cytometry; Robotics; HTLV; Rapid viral diagnosis; Rapid/automated methods - antibiotic sensitivity - bacterial ID; Imaging systems; HPV; MRI + PET (positron emission tomography); Synthetic peptides; Biosensors.

For more details, abstract forms and a preliminary registration form please contact:

Pauline Dudgeon. RAMI-93 Secretariat

Sleights Limited, 14 Dalling Road, London W6 0JB

Tel: 0817417749 Fax: 0817413828

Sponsored by the Association of Medical Microbiologists

\section{BOOKS RECEIVED}

\author{
Viral Hepatitis in China: Problems and Control Strategies. \\ Monographs in Virology, volume 19
}

Edited by Y.-M. Wen. Z.-Y. XU and J. L. Melnick. 1992. ISBN 3-8055-5364-1. S Karger AG, Basel. Pp. 159. £77.90.

The vast burden of viral hepatitis in China amply justifies the inclusion of this monograph in the respected series of Monographs in Virology. The contents have been edited to produce a concise and readable account of all aspects of hepatitis, revealing the breadth of research experience at all levels in China. Reviews from Shanghai on the hepatitis B genome. hepatitis $\mathrm{B}$ replication and the roles of hepadnaviruses in causation of human and duck hepatic tumours are all lucid accounts of recent progress in these fields. Like all chapters in this monograph, they review the extensive local literature on their subject matter, integrating it with the wider international literature, to summarise the directions of Chinese research in the past 15 years and in the near future. A review of the human immune response to hepatitis $B$ is particularly useful. and a section on the epidemiology of hepatitis B in China complements an excellent summary of studies on different vaccination strategies which was the highlight of the monograph for the reviewer. The recent epidemic of hepatitis A in Shanghai will be familiar to most readers, but the comprehensive account of hepatitis $E$ in China. including the local development of diagnostic ELISA tests, summarises developments that have largely been published in local journals only. The final section on treatment of hepatitis B presents little new data on con- ventional antiviral therapy but gives tantalising glimpses of less conventional but promising methods of treatment of both the carrier state and fulminant hepatitis.

The most notable omission from this monograph was any detailed discussion of hepatitis $\mathrm{C}$. The low prevalence of hepatitis $\mathrm{D}$ in general population serosurveys is summarised, but there is no further discussion of epidemiological investigations of this virus targeting at-risk groups, such as drug abusers, has been done in some neighbouring countries. I enjoyed reading this monograph and recommend it to anyone with an interest in hepatitis in developing countries. N. J. BEECHING

\section{Antibiotics and Chemotherapy, volume 44. Pseudomonas aeruginosa in Human Diseases}

Edited by J. Y. Homma, I. A. Holder, N. Hoiby and G. Doring. 1991. ISBN 3-8055-5385-4. S Karger, Basel. Pp. 250. £94.80.

This book is a collection of papers presented at the 3 rd International Symposium on basic research and clinical aspects of Pseudomonas aeruginosa infections, held in Tokyo, 1990. It is already a little beyond its "sell by" date but, nevertheless, it contains relevant information on many aspects of the biology and pathogenesis of $P$. aeruginosa.

The volume is divided into five sections within which are original papers, appraisals and reviews. The quality of 